\title{
Indirect Aggression and Parental Attachment in Early Adolescence: Examining the Role of Perspective Taking and Empathetic Concern
}

Xiaofang $\mathrm{Li}^{1}$, Chenyang Bian ${ }^{1}$, Yanlin Chen ${ }^{1}$, Juan Huang ${ }^{1}$, Yuqiao Ma ${ }^{1}$, Lina Tang ${ }^{1}$, Qiuge Yan ${ }^{1}$, Xiaozhou $\mathrm{Ye}^{1}$, Jie Tang ${ }^{2}$, Yizhen $\mathrm{Yu}^{1 *}$

${ }^{1}$ Department of Child, Adolescence and Woman Health Care, School of Public Health, Tongii Medical College, Huazhong University of Science and Technology, Wuhan, China

${ }^{2}$ School of Public Health, Guangzhou Medical University, Guangzhou, China

*Corresponding author: Yizhen Yu, Department of Child, Adolescence and Woman Health Care, School of Public Health, Tongji Medical College, Huazhong University of Science and Technology, 13rd Hongkong Road, Wuhan, P.R. China, 430030.

E-mail: yuyizhen650@163.com Tel: +86-27-83692709

\begin{abstract}
This study examined the unique and interactive roles of parental attachment and empathy in predicting indirect aggression during early adolescence. A sample of 6,301 early adolescents $(49.2 \%$ boys and $50.8 \%$ girls) in urban China, aged from 11 to 14 years, completed self-administrated measures of parent-adolescent attachment, empathy, and indirect aggression. Results indicated that perspective taking was negatively associated with indirect aggression, and empathetic concern was
\end{abstract}


positively related to indirect aggression. Hierarchical regression analyses revealed that perspective taking moderated the association between empathetic concern and boys' indirect aggression. The findings of this study highlight that empathetic concern might not be a sufficient protective factor of indirect aggression for boys with low levels of perspective taking during early adolescence.

Keywords: Early adolescence; Empathy; Attachment; Indirect Aggression; Moderation

\section{Introduction}

Aggressive behaviors of child and adolescent have been widely researched, while few studies have particularly focused on the subtle, non-physical forms of aggression. It has been given three different names in aggression literature, indirect [1], relational [2], and social aggression[3]. As suggested in an integrated review, the three labels are essentially described the same form of aggression just with minor differences of emphasis [4]. Thus, in this study we adopted the term of indirect aggression, which is not distinguished from relational and social aggression. In contrast to physcial and verbal aggression, indirect aggression is defined as intentionally harming others in covert ways through social manipulation [5], such as using others, spreading rumors, social exclusion, ignoring and rejection [6, 7]. Without face-to-face confrontation, indirect aggression occurs anonymously. For this reason, indirect aggression is hard to identify and its severity is often underestimated. Many researchs found that the consequences of indirect aggression are associated with a series of psychological and behavioral change, including higher levels of depression, anxiety, lower self-esteem, increased physical aggression, drug abuse and even suicide [8, 9]. Long-term emotional damage and social maladjustments are predicted as a victims of indirect aggression [10, $11]$. 
Studies have found that parental attachment and empathy are related to indirect aggression [12, 13]. While many researchers typically focused on the bivariate relationships of empathy or attachment and indirect aggression, a few investigation have examined the role of empathy in relationship between attachment and indirect aggression. Therefore, the purpose of this study was to examine the unique and interactive association between empathy, parental attachment and indirect aggression.

Early adolescence, ages 11 to 14 years, was the context for the current study. According to the development theory outlined by Björkqvist et al. (1992), early children often resort to physical aggressive acts, and then verbal aggression when they verbal skills develop, while individual cannot use indirectly aggressive behaviors until they acquire more advanced verbal skills and social intelligence. Longitudinal studies have shown that indirect aggression is manifested with age during early childhood and peak in early adolescence before declining in later adolescence, which demonstrated a curvilinear relationship with pubertal maturity $[14,15]$. Meanwhile, It is also deemed to be a crucial period when individuals begin to get more autonomy from parents and parental attachment has been shown to decrease [16].

\subsection{Attachment and indirect aggression}

Evidence have shown that secure attachment relationship with parents is associated with less aggression [17-19]. According to Bowlby [20], quality of intimate relationships is originated from pattern of interactions between infants and their early caregivers, primarily the parents. This pattern, also known as "internal working model", is a stable set of expectations and beliefs of oneself, interpretation of the actions of others and how to respond to them. Children who received responsive, sensitive parenting are supposed to construct a positive working model that perceives oneself as 
lovable, others as trustworthy and dependable. Such a secure attachment bond with parents provides a safe base to develop new intimate relationship with more positive expectations [21], and facilitate distress management and emotional regulation [22]. Indeed, several studies suggested that securely attached youths with parents report less indirect aggressive behavior[12] while insecurely attached children with negative working model exhibit more indirect aggression [17, 23, 24].

\subsection{Indirect aggression and empathy}

As an alternative aggressive strategy unique to human beings, indirect aggression necessitate the ability to build and maintain social connections in order to execute social manipulation, such as sharing ones' feeling, inferring ones' emotional status, and understanding the consequence of one's actions on others $[4,25]$. These abilities are often referred to as empathy. Empathy is generally viewed as a multidimensional construct include both affective and cognitive components [26]. Affective empathy (e.g., empathetic concern, EC) is characterized by the tendency to experience and share the emotions of others, which is often related with feelings of sympathy, concern or sorrow for others, whereas cognitive empathy (e.g., perspective taking, PT) is defined as the ability to identify and understand another's social or emotional situation [26-28].

Although numerous studies have demonstrated that empathy inhibit aggressive behavior and facilitate altruistic behavior in adolescents [29, 30], evidence has shown that PT and EC carry different implication for indirect aggression [15, 31]. However, the findings concerning the association between PT and indirect aggression were mixed. For example, Caravita et al. (2009) claimed that indirect aggressors have high level of PT. In line with this, some research argued that individuals high in PT have a superior theory of mind (the ability to attribute mental states to oneself 
and others in order to understand and predict behavior), which serves as a vital premise of social manipulation [25, 32-34]. Conversely, Björkqvist et al. (2000) found that PT is negative associated with indirect aggression. According to the Social Information-processing theory [35], individuals with low PT have social cognitive deficits who cannot make realistic judgments about the intentions of other people, thus leading to the adoption of aggressive behaviors. Yet Richardson et al. found that indirect aggression was related to low PT, but not to EC [36] Moreover, Batanova et.al reported that EC was not associated with indirect aggression either in boys or girls during early adolescence [37].

\subsection{Present study}

The primary goal of this study was to examine the unique and interactive role of mother attachment, father attachment, perspective taking (PT), and empathetic concern (EC) in predicting indirect aggression among early adolescents in urban China.

As discussed earlier, parental attachment was expected to be negatively associated with indirect aggression. Moreover, it is expected that PT would relate to indirect aggression while EC would not relate to indirect aggression. Due to the conflicting findings, it is unclear whether high PT or low PT is related to indirect aggression. In addition, Van der Graaff et al. found that empathy mediated in the relationship between perceived parental support and aggressive behavior in a sample of 323 Dutch adolescents [38]. Furthermore, empathy has also been examined as a moderator in the relations between parenting behavior and child conduct problems [39]. As such, we further hypothesized that empathy (PT and EC) would moderate the relationship between parental attachment and indirect aggression in56 mother-child dyads. Based on earlier studier concerning the interactive effect of two components of empathy on aggression $[15,37]$, we hypothesized that PT and EC would be interacted 
in predicting indirect aggression among Chinese early adolescents, even though the hypothesis has not been empirically supported in Western societies. Based on research indicating that girls worry more about relationships and are more indirectly aggressive than boys [40], we expected that female and male might have different mechanism in understanding the links between empathy, parental attachment and indirect aggression.

\section{Methods}

\subsection{Participants and procedure}

The data came from a national survey of junior and senior high school students conducted in five provinces (including Hubei, Yunnan, Anhui, Heilongjiang and Guangdong) of China, which has been designed to explore the impacting factors of aggression. We conducted a two-stage stratified randomized cluster sample survey with the class as the basic sampling unit. Firstly, 15 cities were selected from 5 provinces according to the economic status. Secondly, for all the public middle schools in the 15 cities, 82 middle schools were selected using the systematical sampling method. Within each selected class, all students were included in the survey except those with severe mental illness. Finally, 15,738 participants were recruited and returned their questionnaires. We included a total of 6301 early adolescents aged from 11 to 14 years $(M=13.13, S D=0.80)$ for current analysis. Of them 3,102 (49.20\%) were boys, 3,199 (50.80\%) were girls.

Participants were asked to fill in a self-reported questionnaire in a 45-minutes class at school with the guidance of trained investigators. Before the survey, informed consents were gotten from all target schools and parents or the next of kin, caretakers, or guardians were obtained and documented.

\subsection{Measures}


Indirect Aggression. Indirect aggression was assessed by 6 items in Chinese version of Buss-Warren Aggression Questionnaire (BWAQ) [41]. Items were scored on a 5-point Likert-type scale format ranging from 1 (Extremely uncharacteristic of me) to 5 (Extremely characteristic of me). High scores reflect more indirect aggressive behavior. The internal consistency reliability of the indirect aggression subscale for the current sample was 0.71 and 0.73 for girls and boys, respectively.

Attachment. Parent section of the Inventory of Parent and Peer attachment (IPPA) [42] was used to assess adolescents' parental attachment. The IPPA was a self-reported questionnaire rated on a 5-point Likert-type scale format $(1=$ almost never or never true; $5=$ almost always or always true $)$. The scale contains 25 items of three subscales of communication, trust and alienation. Items were summed up with items of alienation scale reverse-scored. Father and mother attachment was evaluated respectively with parallel wordings of items. The Chinese version of IPPA has been demonstrated good reliability in Chinese samples [43]. The internal consistency estimate in this study for mother attachment was 0.83 and 0.76 for boys and girls respectively; the internal consistency for father attachment was 0.78 and 0.75 for boys and girls respectively.

Empathy. Empathy was measured by two subscales from a Chinese version of Interactional Reactivity Index (IRI-C) [44], 7-item subscale of perspective taking (PT) and 7-item of empathetic concern (EC). Items were rated on a 5-point scale ranging from 1 (almost never or never true) to 5 (almost always or always true) and were summed up so that higher scores represented greater empathy. In present study, the internal consistency reliability for PT was 0.65 and 0.68 for boys and girls, respectively; the internal consistency for EC was 0.65 and 0.70 for boys and girls, respectively.

\section{Results}


Prior to primary analyses, the homogeneity of covariance matrices of all study variables across gender was assessed by Box's $M$ test. Results indicated that the variance-covariance matrices significantly varied across gender (Box's $M=83.91, F(15)=5.59, P<0.001$ ). Therefore, the following analyses were conducted separately for girls and boys.

Zero-order correlations among all study variables were conducted separately by gender (see Table 1). Mother and father attachment was negatively associated with adolescents' indirect aggression and positively related to both components of empathy. PT was negatively associated with indirect aggression. While no significant association was found between EC and indirect aggression. Additionally, both components of empathy were positively related to each other.

Hierarchical linear regression analyses were performed to examine the study hypotheses. Two hierarchical multiple regression analyses were performed separately by gender to examine the study hypotheses. All predicting variables were centered (the actual score minus the mean score) to avoid the problem of multicollinearity in the regression. Interaction items were created by calculating the product of the centered independent variables. As guided by Aiken and West [45], two-way interactions were examined in presence of all main effects separately and by gender. The covariates were entered in step 1(age in years), then the predictors (parental-child attachment) were entered in step 2 and the potential moderators (PT and EC) were entered in step 3, then the interaction items (predictor $\times$ moderator) were entered in the regression model in step 4. Two way interactions examined individually in the presence of all main effects. The effect of the moderation model can be detected by the change of $R^{2}$ from step 3 to step 4 . The two-way interactions assessed whether (1) empathy (EC and/or PT) moderated the relationship between parental attachment and indirect aggression, and (2) PT moderated the relations between EC and indirect aggression 
Table 2 reported the standardized beta coefficient and changed in R-squares for girls and boys, respectively. Examination of the main effect models (see step 3) showed that after adjusting for age, parental attachment, two components of empathy were significant predictors of indirect aggression both for boys $[F(4,3096)=54.27, P<0.001]$ and girls $[F(4,3193)=27.11, P<0.001]$. Age, however, was positively and significantly associated with indirect aggression for girls only. Examination of the two-way interaction suggested that the interaction between PT and EC in predicting indirect aggression was significant only among boys $\left[R^{2}\right.$ change $\left.=.001, F(1,3095)=4.42, P<0.05\right]$.

Furthermore, to better interpret and understand the nature of moderation effect, the simple slope test was conducted at a high point (1.96 SD above the mean) and a low point (1.96 SD below the mean) of the predictor with all target variables standardized $(M=0, S D=1)$. Based on the principle of approximate normal distribution, the cutoff value of $95 \%$ confidence interval was adopted in this study.

As depicted in Fig 1, probing the interaction between PT and EC showed that EC was positively associated with indirect aggression for boys with low PT $(b=0.150, t=4.174, P<0.001)$, but the relations were not significant for boys with high levels of PT $(b=0.038, t=0.434, P=0.664)$.

\section{Discussion}

The main purpose of this study was to determine the unique and interactive role of parental attachment and different components of empathy in predicting indirect aggression. Results showed that parental attachment and empathy were significant negative predictors of indirect aggression. As hypothesized, PT and EC acted differently in predicting indirect aggression. Study findings indicated that among boys only, PT moderated the association between EC and indirect aggression. 
Unexpectedly, neither PT nor EC were moderated the association between parental attachment and indirect aggression. The lack of significant findings might be attributed to other related factors that confound the relationship between parental attachment and aggression, such as perceived parental need support [46], family or school factors [37], social status [15], and self-esteem [12].

Correlation and regression analysis indicated that secure parental attachment was negatively associated with indirect aggression. According to the attachment theory, a stable internal working model deeply rooted in early interactions with parents could be used to explain the continuity of intimate relationships from childhood to adulthood. This finding supports the current literature, which document the importance of parental attachment on indirect aggression. As suggested by Larson and his collages (1996), adolescents securely attached with parents have greater psychosocial competence, more positive coping strategy and less aggressive[47].

As hypothesized, PT was negatively associated with indirect aggression. This finding was supports previous studies indicated that individual high in perspective taking may be less likely than their peers to hurt others [29]. Conversely, individuals with low PT have a impaired ability to apprehend, appreciate, or tolerate viewpoints of others [31], and unable to understand the link between aggressive behaviors and sufferings of the victim [30], thus were more likely to engage in indirect aggression [48].

As predicted, correlation analysis revealed that EC was not related to indirect aggression. However, after controlling for age, parental attachment and perspective taking, the unique variable of EC was positively contributed to indirect aggression. Although empirical and theoretical literature have showed that feelings of concern and sympathy toward others were significant predictor of 
decreases in aggression [49], this finding is not completely unexpected. For instance, Cliffordson (2000)found positive links between EC and personal distress [50]. Personal distress, a self-focused, aversive emotional reaction to the vicarious experiencing of another's emotion, was reported to be positively associated with aggression [51, 52]. Beside, Hawk et.al (2013)argued that EC was related to emotion regulation difficulties, including social anxiety and neuroticism [53]. While social anxiety has been found to be positively associated with indirect aggression during early adolescence [40]. It is possible that relatively high level of empathetic concern might add to individuals' emotional vulnerability and personal distress, such as insecurity, helplessness, victim-blaming, social anxiety. As such, EC might not be a sufficient protective factor but a potential instable factor of indirect aggression under certain circumstances.

Partially support of our hypothesis, PT and EC was interacted in predicting indirect aggression but only among boys (not among girls). As such, for boys with low PT, high EC correspond to more indirect aggression. One possible reason is that boys high in EC are better at reading and experiencing others' feelings, which make it possible for one to fit into the peer group and create desirable social relationships for social manipulation. Another explanation may be that for boys low in PT, feelings of concern and care for others would facilitate oneself to defend or retaliate using aggressive strategy. In this perspective, the findings were in line with prior research arguing that affective empathy was associated with boys' defending behavior [15, 54].

There are also some limitations that warrant discussion. First, indirect aggression was assessed by the self-reported measure because indirect aggression is covert and hard to notice. However, self-reported indirect aggression may be less reliable as indirect aggressors tend to conceal their intentions. In this perspective, appraisal from multiple reporters including the aggressors and the 
victims may be helpful. Second, given the nature of cross-section study, experimental research and longitudinal study is needed to confirm the findings. Lastly, the findings warrant cautious interpretation given the sufficient of beta and change of $\mathrm{R}^{2}$ is relatively is small to moderate.

Despite these limitations, present study has challenged some tradition conceptions of aggression by pointing out that EC might not be a sufficient protective factor but a latent exacerbating factor of indirect aggression for boys with low PT among Chinese early adolescents. Present study is also of great important as few of the evidence of potential positive association between EC and indirect aggression. In all, the findings are helpful for better understanding of the internal psychological mechanism of interaction of two components of empathy, parental attachment in predicting indirect aggression and for making intervention recommendations of indirect aggression during early adolescence.

\section{Conclusion}

This study extends current literature by examining the unique and interactive association between different components of empathy, parental attachment and indirect aggression. While perspective taking was negatively associated with indirect aggression, and empathetic concern was positively related to indirect aggression. It is noteworthy that two components of empathy are interacted in predicting boys' indirect aggression. In this paper we presented a tentative explanation, more studies are needed to clarify the mechanism across gender in understanding the interactive role of two components of empathy in predicting indirect aggression. 


\section{References}

1. Björkqvist, K., K. Österman, and A. Kaukiainen, The development of direct and indirect aggressive strategies in males and females, in Of mice and women: Aspects of female aggression, N. Björkqvist K, P, Editor. 1992, Academic Press: San Diego, US.

2. Crick, N.R., Relational aggression: The role of intent attributions, feelings of distress, and provocation type. Development and psychopathology, 1995. 7: p. 313-313.

3. Underwood, M.K., B.R. Galenand, and J.A. Paquette, Top ten challenges for understanding gender and aggression in children: Why can't we all just get along? Social development, 2001. 10(2): p. 248-266.

4. Archer, J. and S.M. Coyne, An integrated review of indirect, relational, and social aggression. Personality and Social Psychology Review, 2005. 9(3): p. 212-230.

5. Björkqvist, K., K.M. Lagerspetz, and A. Kaukiainen, Do girls manipulate and boys fight? Developmental trends in regard to direct and indirect aggression. Aggressive behavior, 1992. 18(2): p. 117-127.

6. Feshbach, N. and G. Sones, Sex differences in adolescent reactions toward newcomers. Developmental Psychology, 1971. 4(3): p. 381.

7. Garandeau, C.F. and A.H.N. Cillessen, From indirect aggression to invisible aggression: A conceptual view on bullying and peer group manipulation. Aggression and Violent Behavior, 2006. 11(6): p. 612-625.

8. Craig, W.M., The relationship among bullying, victimization, depression, anxiety, and aggression in elementary school children. Personality and individual differences, 1998. 24(1): p. 123-130.

9. Twenge, J.M., et al., If you can't join them, beat them: effects of social exclusion on aggressive behavior. Journal of personality and social psychology, 2001. 81(6): p. 1058.

10. Crick, N.R. and J.K. Grotpeter, Relational aggression, gender, and social - psychological adjustment. Child development, 1995. 66(3): p. 710-722.

11. Werner, N.E. and N.R. Crick, Maladaptive peer relationships and the development of relational and physical aggression during middle childhood. Social Development, 2004. 13(4): p. 495-514.

12. Gomez, R. and S. McLaren, The inter - relations of mother and father attachment, self - esteem and aggression during late adolescence. Aggressive Behavior, 2007. 33(2): p. 160-169.

13. Kaukiainen, A., et al., The relationships between social intelligence, empathy, and three types of aggression. Aggressive behavior, 1999. 25(2): p. 81-89.

14. Cairns, R.B., et al., Growth and aggression: I. Childhood to early adolescence. Developmental Psychology, 1989. 25(2): p. 320.

15. Caravita, S.C.S., P. Di Blasio, and C. Salmivalli, Unique and Interactive Effects of Empathy and Social Status on Involvement in Bullying. Social Development, 2009. 18(1): p. 140-163.

16. Papini, D.R., L.A. Roggman, and J. Anderson, Early-Adolescent Perceptions of Attachment to Mother and Father A Test of the Emotional-Distancing and Buffering Hypotheses. The Journal of Early Adolescence, 1991. 11(2): p. 258-275.

17. Michiels, D., et al., Parent-child interactions and relational aggression in peer relationships. Developmental Review, 2008. 28(4): p. 522-540.

18. Nelson, D.A., Crick, N R, Parental psychological control: Implications for childhood physical and relational aggression. Intrusive parenting: How psychological control affects children and adolescents, 
ed. B.K. Barber. 2002, Washington, DC: American Psychological Association. 168-189.

19. Simons, K.J., C.E. Paternite, and C. Shore, Quality of parent/adolescent attachment and aggression in young adolescents. Journal of Early Adolescence, 2001. 21(2): p. 182-203.

20. Bowlby, J., Attachment And Loss. Vol. 2: Separation: Anxiety And An. 1973: Evt. Penguin books.

21. Ainsworth, M.D., Object relations, dependency, and attachment: A theoretical review of the infant-mother relationship. Child development, 1969. 40(4): p. 969-1025.

22. Mikulincer, M. and P.R. Shaver, Boosting attachment security to promote mental health, prosocial values, and inter-group tolerance. Psychological Inquiry, 2007. 18(3): p. 139-156.

23. Rubin, K.H. and R.S. Mills, Conceptualizing developmental pathways to internalizing disorders in childhood. Canadian Journal of Behavioural Science/Revue canadienne des sciences du comportement, 1991. 23(3): p. 300.

24. Talebi, B.Z. and P. Verma, Aggression and attachment security. Iranian Journal of Psychiatry, 2007. 2(2): p. 72-77.

25. Sutton, J., P.K. Smith, and J. Swettenham, Social cognition and bullying: Social inadequacy or skilled manipulation? British Journal of Developmental Psychology, 1999. 17(3): p. 435-450.

26. Davis, M.H., A multidimensional approach to individual differences in empathy. Catalog of Selected Documents in Psychology 1980. 10: p. 85.

27. Eisenberg N, S.J., Empathy and Its Development. 1987, New York: Cambridge University Press.

28. Hogan, R., Development of an empathy scale. J Consult Clin Psychol, 1969. 33(3): p. 307-16.

29. Björkqvist, K., K. Österman, and A. Kaukiainen, Social intelligence-empathy= aggression? Aggression and Violent Behavior, 2000. 5(2): p. 191-200.

30. Jolliffe, D. and D.P. Farrington, Examining the relationship between low empathy and bullying. Aggressive Behavior, 2006. 32(6): p. 540-550.

31. Yeo, L.S., et al., The role of affective and cognitive empathy in physical, verbal, and indirect aggression of a Singaporean sample of boys. J Psychol, 2011. 145(4): p. 313-30.

32. Andreou, E., Bully/victim problems and their association with Machiavellianism and self - efficacy in Greek primary school children. British Journal of Educational Psychology, 2004. 74(2): p. 297-309.

33. Konrath, S., et al., The relationship between narcissistic exploitativeness, dispositional empathy, and emotion recognition abilities. Journal of Nonverbal Behavior, 2014. 38(1): p. 129-143.

34. Sutton, J., P.K. Smith, and J. Swettenham, Bullying and 'Theory of Mind': A Critique of the 'Social Skills Deficit' View of Anti-Social Behaviour. Social Development, 1999. 8(1): p. 117-127.

35. Crick, N.R. and K.A. Dodge, A review and reformulation of social information-processing mechanisms in children's social adjustment. Psychological Bulletin, 1994. 115(1): p. 74-101.

36. Richardson, D.R., et al., Empathy as a cognitive inhibitor of interpersonal aggression. Aggressive Behavior, 1994. 20(4): p. 275-289.

37. Batanova, M. and A. Loukas, Unique and interactive effects of empathy, family, and school factors on early adolescents' aggression. J Youth Adolesc, 2014. 43(11): p. 1890-902.

38. Van der Graaff, J., et al., The moderating role of empathy in the association between parental support and adolescent aggressive and delinquent behavior. Aggress Behav, 2012. 38(5): p. 368-77.

39. Miller, N.V., C.J. Johnston, and D.S. Pasalich, Parenting and Conduct Problems: Moderation by Child Empathy. Journal of Psychopathology and Behavioral Assessment, 2014. 36(1): p. 74-83.

40. Loudin, J.L., A. Loukas, and S. Robinson, Relational aggression in college students: Examining the roles of social anxiety and empathy. Aggressive Behavior, 2003. 29(5): p. 430-439.

41. Maxwell, J.P., Psychometric properties of a Chinese version of the Buss-Warren Aggression 
Questionnaire. Personality and Individual Differences, 2008. 44(4): p. 943-953.

42. Armsden, G.C. and M.T. Greenberg, The inventory of parent and peer attachment: Individual differences and their relationship to psychological well-being in adolescence. Journal of youth and adolescence, 1987. 16(5): p. 427-454.

43. Song, H., R.A. Thompson, and E. Ferrer, Attachment and self-evaluation in Chinese adolescents: age and gender differences. Journal of adolescence, 2009. 32(5): p. 1267-86.

44. Siu, A.M.H. and D.T.L. Shek, Validation of the Interpersonal Reactivity Index in a Chinese Context. Research on Social Work Practice, 2005. 15(2): p. 118-126.

45. Aiken, L.S., \& West, S. G., Multiple Regression: Testing and Interpreting Interactions. 1985, Newbury Park, CA: Sage.

46. Miklikowska, M., B. Duriez, and B. Soenens, Family roots of empathy-related characteristics: The role of perceived maternal and paternal need support in adolescence. Developmental psychology, 2011. 47(5): p. 1342.

47. Larson, R.W., et al., Changes in adolescents' daily interactions with their families from ages 10 to 18 : Disengagement and transformation. Developmental Psychology, 1996. 32(4): p. 744.

48. Espelage, D.L. and S.M. Swearer, Bullying in American schools: A social-ecological perspective on prevention and intervention. 2004: routledge.

49. Lovett, B.J. and R.A. Sheffield, Affective empathy deficits in aggressive children and adolescents: a critical review. Clinical psychology review, 2007. 27(1): p. 1-13.

50. Cliffordson, C., The hierarchical structure of empathy: dimensional organization and relations to social functioning. Scand J Psychol, 2002. 43(1): p. 49-59.

51. Batson, C.D., J. Fultz, and P.A. Schoenrade, Distress and empathy: Two qualitatively distinct vicarious emotions with different motivational consequences. Journal of personality, 1987. 55(1): p. 19-39.

52. Eisenberg, N., \& Eggum, N. D. , Empathic responding: Sympathy and personal distress. The social neuroscience of empathy, 2009: p. 71-83.

53. Hawk, S.T., et al., Examining the Interpersonal Reactivity Index (IRI) Among Early and Late Adolescents and Their Mothers. Journal of Personality Assessment, 2013. 95(1): p. 96-106.

54. Barchia, K. and K. Bussey, Individual and collective social cognitive influences on peer aggression: exploring the contribution of aggression efficacy, moral disengagement, and collective efficacy. Aggress Behav, 2011. 37(2): p. 107-20. 
Table 1. Zero-order Correlations and Descriptive statistics for All Study Variables for Girls ( $n=3199)$ and Boys( $n=3102)$

\begin{tabular}{lcccccc}
\hline \multicolumn{1}{c}{ Variables } & 1 & 2 & 3 & 4 & 5 & 6 \\
\hline 1. Age & - & .014 & $-.074 * * *$ & $-.069 * * *$ & .009 & -.018 \\
\hline 2. Indirect Aggression & $.086^{* * *}$ & - & $-.211^{* * *}$ & $-.191^{* * *}$ & $-.130^{* * *}$ & .017 \\
3. Mother attachment & $-.108^{* * *}$ & $-.263^{* * *}$ & - & $.548^{* * *}$ & $.307^{* * *}$ & $.210^{* * *}$ \\
4. Father attachment & $-.115^{* * *}$ & $-.225^{* * *}$ & $.556^{* * *}$ & - & $.260^{* * *}$ & $.169^{* * *}$ \\
5. Perspective taking & -.009 & $-.148^{* * *}$ & $.255^{* * *}$ & $.238^{* * *}$ & - & $.413^{* * *}$ \\
6. Empathetic concern & $.040^{*}$ & .021 & $.155^{* * *}$ & $.127^{* * *}$ & $.396^{* * *}$ & - \\
\multicolumn{1}{c}{ Girls' M (SD) } & $13.10(0.81)$ & $12.15(3.90)$ & $88.34(17.52)$ & $86.46(18.47)$ & $22.97(4.67)$ & $25.12(4.11)$ \\
\multicolumn{1}{c}{ Boys M (SD) } & $13.15(0.79)$ & $12.07(4.03)$ & $87.79(15.86)$ & $87.00(16.71)$ & $22.39(4.70)$ & $24.58(4.13)$ \\
\hline
\end{tabular}

Values above the diagonal are for males and values below the diagonal are for females.

$* p<0.05, * * * P<.001$. 
Table 2. Hierarchical Regression Predicting Aggression form Parental Attachment and Empathy in Early Adolescence

\begin{tabular}{|c|c|c|c|c|c|c|c|c|}
\hline & \multicolumn{4}{|c|}{ Girls results } & \multicolumn{4}{|c|}{ Boys results } \\
\hline & Step 1 & Step 2 & Step 3 & Step 4 & Step 1 & Step 2 & Step 3 & Step \\
\hline Age (in years) & $.086^{* * *}$ & $.052^{* *}$ & $.049 * *$ & & .014 & -.004 & -.001 & \\
\hline Mother attachment (MA) & & $-.196 * * *$ & $-.189 * * *$ & & & $-.152^{* * *}$ & $-.146 * * *$ & \\
\hline Father attachment (FA) & & $-.109 * * *$ & $-.100 * * *$ & & & $-.108 * * *$ & $-.103 * * *$ & \\
\hline Perspective taking (PT) & & & $-.119 * * *$ & & & & $-.103 * * *$ & \\
\hline Empathetic concern (EC) & & & $.108 * * *$ & & & & $.107^{* * *}$ & \\
\hline $\mathrm{PT} \times \mathrm{EC}$ & & & & -.012 & & & & $-.037 *$ \\
\hline $\mathrm{MA} \times \mathrm{EC}$ & & & & $.050 * *$ & & & & -.014 \\
\hline $\mathrm{FA} \times \mathrm{PT}$ & & & & -.014 & & & & -.010 \\
\hline $\mathrm{MA} \times \mathrm{PT}$ & & & & -.009 & & & & -.027 \\
\hline$F A \times E C$ & & & & .032 & & & & -.016 \\
\hline \multirow[t]{2}{*}{$\Delta R^{2}$} & $.007^{* * *}$ & $.073^{* * *}$ & $.015^{* * *}$ & .000 & .000 & $.053^{* * *}$ & $.013^{* * *}$ & $.001 *$ \\
\hline & & & & $.002 *$ & & & & .000 \\
\hline
\end{tabular}

$* P<0.05, * * P<0.01, * * * P<.001$

Two way interactions examined individually in the presence of all main effects. 


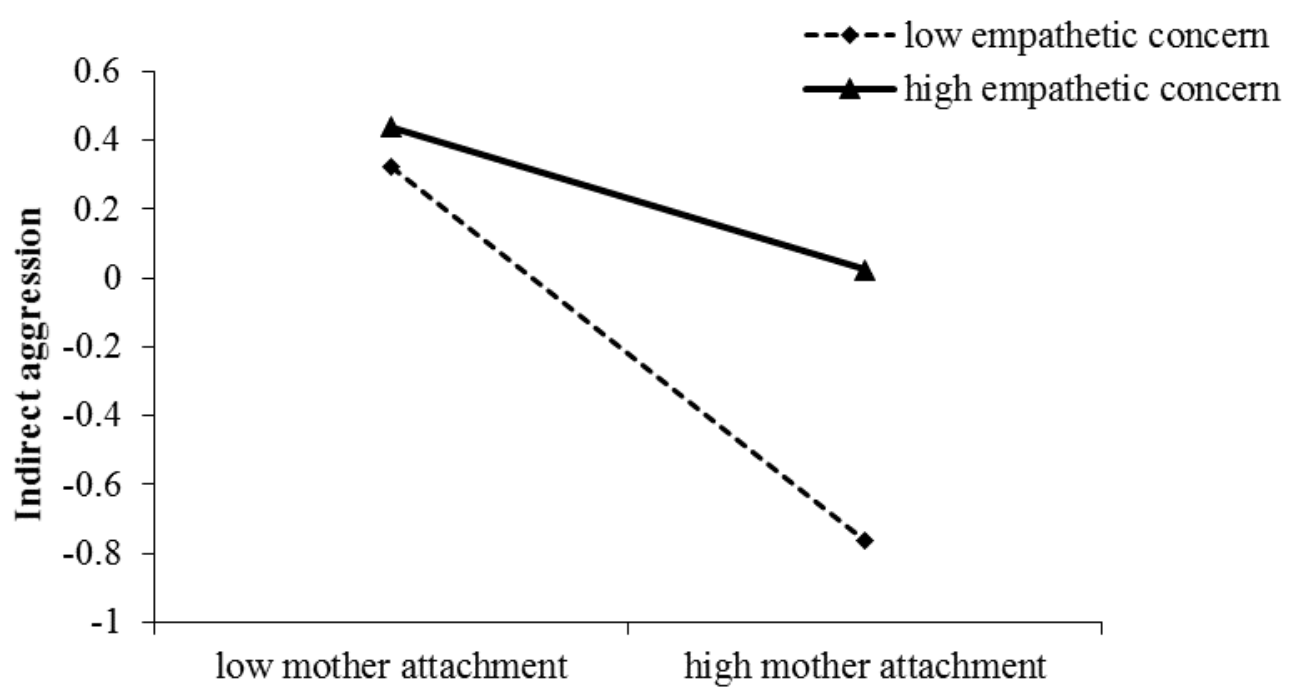

Fig. 1 Examining the interaction between mother attachment and empathetic concern for girls' indirect aggression

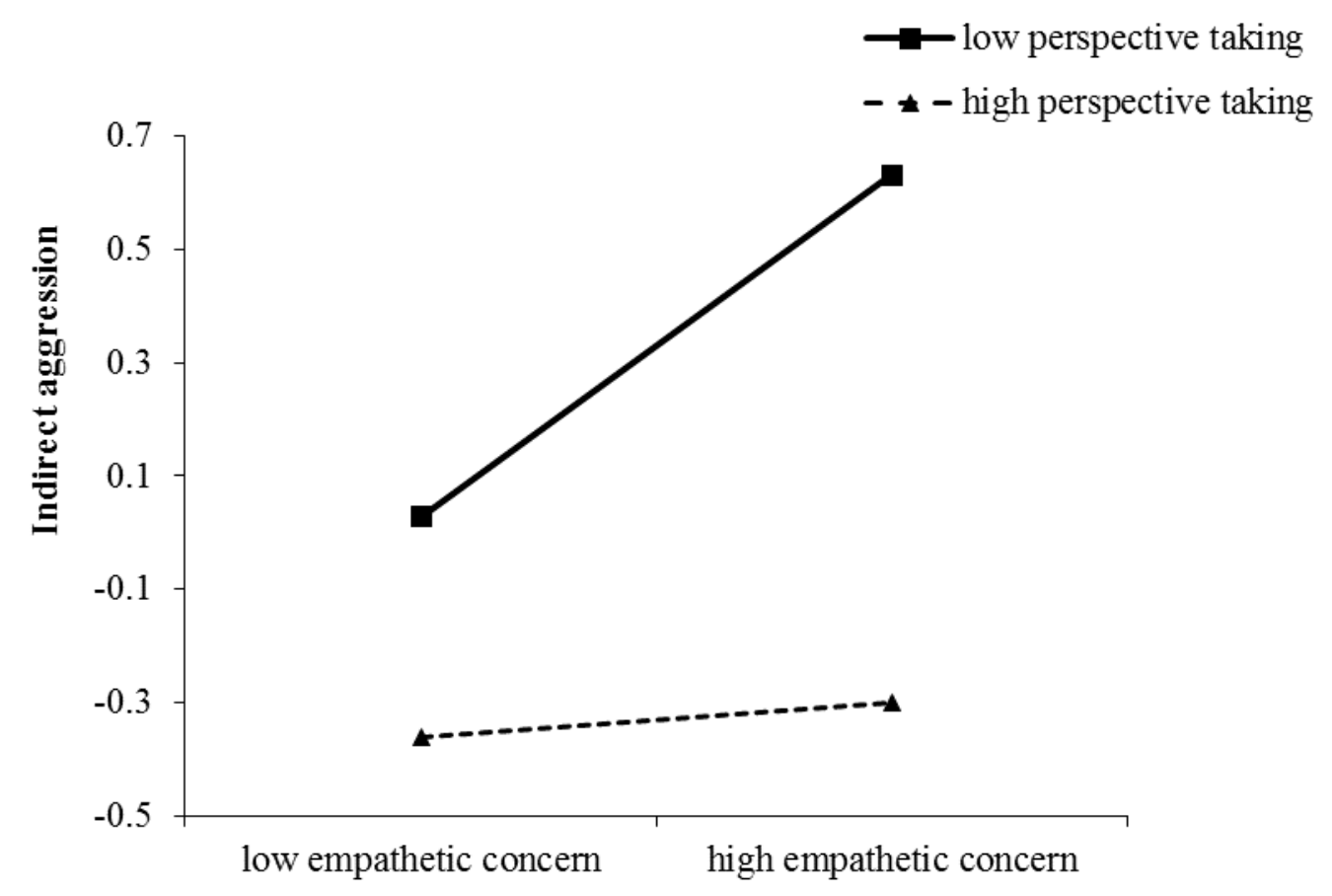

Fig. II. interaction between perspective taking and empathetic concern in predicting indirect aggression 